\title{
Intriguing Interaction of Bacteriophage-Host Association: An Understanding in the Era of Omics
}

\author{
Krupa M. Parmar ${ }^{1 *}$, Saurabh L. Gaikwad ${ }^{1}$, Prashant K. Dhakephalkar ${ }^{1}$, Ramesh Kothari ${ }^{2}$ \\ and Ravindra Pal Singh ${ }^{2 * t}$
}

${ }^{1}$ Bioenergy Group, Agharkar Research Institute, Pune, India, ${ }^{2}$ Department of Biosciences, Saurashtra University, Rajkot, India

OPEN ACCESS

Edited by:

Florence Abram,

NUI Galway, Ireland

Reviewed by:

Steven Ripp,

University of Tennessee, Knoxville,

USA

Sanna Sillankorva, University of Minho, Portugal

*Correspondence:

Krupa M. Parmar krupa111091@yahoo.co.in

Ravindra Pal Singh

ravindrapal.1441@gmail.com

${ }^{\dagger}$ Present Address:

Ravindra Pal Singh,

Department of Biological Chemistry, John Innes Centre, Norwich Research

Park, Norwich, UK

Specialty section:

This article was submitted to Microbiotechnology, Ecotoxicology and Bioremediation,

a section of the journal

Frontiers in Microbiology

Received: 03 January 2017 Accepted: 16 March 2017

Published: 07 April 2017

Citation:

Parmar KM, Gaikwad SL,

Dhakephalkar PK, Kothari R and Singh RP (2017) Intriguing Interaction

of Bacteriophage-Host Association: An Understanding in the Era of Omics.

Front. Microbiol. 8:559.

doi: 10.3389/fmicb.2017.00559
Innovations in next-generation sequencing technology have introduced new avenues in microbial studies through "omics" approaches. This technology has considerably augmented the knowledge of the microbial world without isolation prior to their identification. With an enormous volume of bacterial "omics" data, considerable attempts have been recently invested to improve an insight into virosphere. The interplay between bacteriophages and their host has created a significant influence on the biogeochemical cycles, microbial diversity, and bacterial population regulation. This review highlights various concepts such as genomics, transcriptomics, proteomics, and metabolomics to infer the phylogenetic affiliation and function of bacteriophages and their impact on diverse microbial communities. Omics technologies illuminate the role of bacteriophage in an environment, the influences of phage proteins on the bacterial host and provide information about the genes important for interaction with bacteria. These investigations will reveal some of bio-molecules and biomarkers of the novel phage which demand to be unveiled.

Keywords: bacteriophage, genomics, next-generation sequencing, transcriptomics

\section{INTRODUCTION}

Innovations in next-generation sequencing (NGS) technology and the decline in the sequencing cost have triggered a revolution to gain an understanding into the diversity, structure, and function of complex microbial processes (Vlahou and Fountoulakis, 2005). NGS has enhanced our concept of various influences of microbes in maintaining equilibrium in the environment and accentuating the function of diverse hosts including humans (Li et al., 2008). NGS has expedited the interpretation of microbiome using techniques, such as metagenomics, metatranscriptomics, metabolomics, proteomics, and single cell genomics. Apart from sequencing, bioinformatics and statistical tools also represent a significant role in sequence assembly, alignment, binning, and annotation. Software of bioinformatic assists in decoding the identity, abundance profile, genetic composition and functional channels of an organism or for a microbial community (Meyer et al., 2008; Glass et al., 2010). Genomics deals with sequencing of the whole genome of a distinct organism whilst metagenomics study a pool of genomes of a community of different populations (Handelsman, 2004). According to the central dogma, the flow of genetic information in a cell is from DNA (genome) to RNA (transcriptome) and then it is translated into proteins (proteome) (Crick, 1970). Genomics elucidates presence of the gene in an organism, while transcriptomics provides the information about the genes that are actively expressed in an organism and proteomics 
study the structure and function of every protein in an organism. A novel technique called single cell genomics takes in record information of the sequence from an individual cell which procures a better degree of accuracy in cellular differences and a finer understanding into the function of a particular cell in an ecosystem (Eberwine et al., 2014). However, metabolomics includes the analysis of metabolites of an organism and these results may vary from genomics and transcriptomics data as they are influenced by surrounding environments (Apel and Hirt, 2004). Apart from sequencing, bioinformatics and statistical tools assist in sequence assembly, alignment, binning and annotation.

Whilst, the information about bacteria present on earth is better understood, data regarding viruses particularly bacteriophages (henceforth called phages) is still in its infancy. Phages are the most abundant and diverse group of viruses found on Earth (Short and Suttle, 2005). Interactions between the bacterial host and phage have significanty played an role in biogeochemical cycles, regulation of the microbial community structures and governing the microbial populations (Figure 1). Recent surveys have documented the capacity of phages in maintaining the stability of microflora in the human gut (Minot et al., 2011) and regulation of pathogen and multidrug resistance (MDR) in the environment (Parmar et al., 2017). In bacteria, 16S rRNA genes and several house-keeping genes serve as a biomarker which facilitate their identification, whereas, there is an absence of biomarker gene among phages, which poses as a hindrance for identification of phages and hence the phage database is quite insufficient (Edwards and Rohwer, 2005). Addressing the challenge to design a biomarker for phages may uncover new avenues in better understanding the virosphere. Plaque assay being a culture-dependent technique isolates a specific phage against a bacterial host. Subsequently, their identification can be worked out using phenotypic characteristics and sequencing (Sanchez et al., 2015). In an approach to improve a comprehensive insight into uncultivable phage and their interaction with the bacterial host, this review summarizes different NGS techniques and the bioinformatics tools that are applied to evaluate such data.

\section{BACTERIOPHAGES AND THEIR INTERACTION WITH BACTERIAL HOST}

Phages are in 10:1 ratio with bacteria on Earth, though viral DNA corresponds to only $0.1 \%$ of total DNA among microbial communities (Qin et al., 2010). Phages are ubiquitous in the environment and are found abundantly where bacterial hosts thrive. Mostly phages flourish in oceans, soil, wastewater treatment plants, hot-water springs and animal gut (Wommack and Colwell, 2000; Prigent et al., 2005; Prestel et al., 2008; Srinivasiah et al., 2008). Phages are classified on the basis of their size, structural composition, genome organization and on the host it infects (Ackermann, 2009). Electron microscopy assists in studying phenotypic characteristics of phage on the basis of the size and shape of head, tail and tail fibers. The most abundant phages in the environment are dsDNA belonging to order Caudovirales (Weinbauer and Rassoulzadegan, 2004).
Caudovirales are furthermore classified into Podoviridae having a short tail, Siphoviridae with long non-contractile tail and Myoviridae possessing a long contractile tail. Every phage is specific toward a particular bacterial host and may have a narrow or broad host range depending on its infection capability. Hosts provide the enzymatic machinery for the phages to replicate and multiply by infecting the most active (exponentially growing) bacteria as implied by "kill the winner" hypothesis (Rodrigue et al., 2009). Phages undergo two types of life cycles, (1) in the lytic lifecycle, phage injects own DNA into a host cell and multiply by manipulating host replicating machinery. After replication, phage cleaves the host bacterial cells releasing progeny virus particles into the environment. Whereas, in (2) lysogeny lifecycle, phage DNA integrates into the bacterial genome, replicates their DNA along the bacterial genome and transfer on to the progeny of host cells (Bertani, 1951).

The interplay between host and phage particle initiates as soon as the phage recognizes specific receptors on the bacterial cell wall. The tail proteins of phage particle recognize the receptor protein(s) of bacteria and inject own DNA into host cytoplasm choosing either lytic or lysogenic lifecycle. Once the phage DNA is inserted into the bacterial cell, the cell is termed as a "virocell" carrying virus auxiliary metabolic genes (vAMGs), which are believed to augment the metabolic potential of the host during infection process as shown in Figure 1 (Rosenwasser et al., 2016). The phages acquire new genes into their genomes by interactions with the host genome in order to replicates in the host cells. The bacterial genes that attach near to the prophage attachment site, suggests the genes were acquired by inaccurate prophage excision. Some novel genes can similarly be transmitted into the interior part of the genome by some unexplained mechanism (Juhala et al., 2000). However, these genes may be autonomous transcripts or repressed prophages that provide benefit to hosts (Brüssow et al., 2004). Horizontal gene transfer (HGT) by these phage particles from one host to another host genomes, results in an increased microbial diversity (Dutta and Pan, 2002; Weinbauer and Rassoulzadegan, 2004). Thus, the interaction between phage and host chiefly emphasizes the structure of microbial communities (Rohwer and Thurber, 2009). Some genes derived by phage also aid in nutrient cycling and gear up the biogeochemical cycles on Earth. Furthermore, phages have a crucial aspect in host mortality, carbon cycling (Breitbart et al., 2004) and nutrient cycling (Suttle, 2007). Also, microbial lysis by phage infection has significance in bacterial population control and the debris of these dead microbes act as a food source in the food web of the environment (SimeNgando and Colombet, 2009), thus involved the cycling nutrients (Figure 1). Phages are thus accounted as an application to limit bacterial pathogens and multi-drug resistant organisms in the environment by the mechanism of specifically lysing the bacterial hosts (Parmar et al., 2017). Despite an immense abundance and diversity of phages and their reimbursement in the global webs, molecular knowledge of phage-host interactions is missing. In the era of NGS, employing genomics, single cell genomics, transcriptomics, proteomics, and metabolomics can be a smart attempt to understand the interaction among the phages and their bacterial hosts (Figure 2). A review of the literature has been 


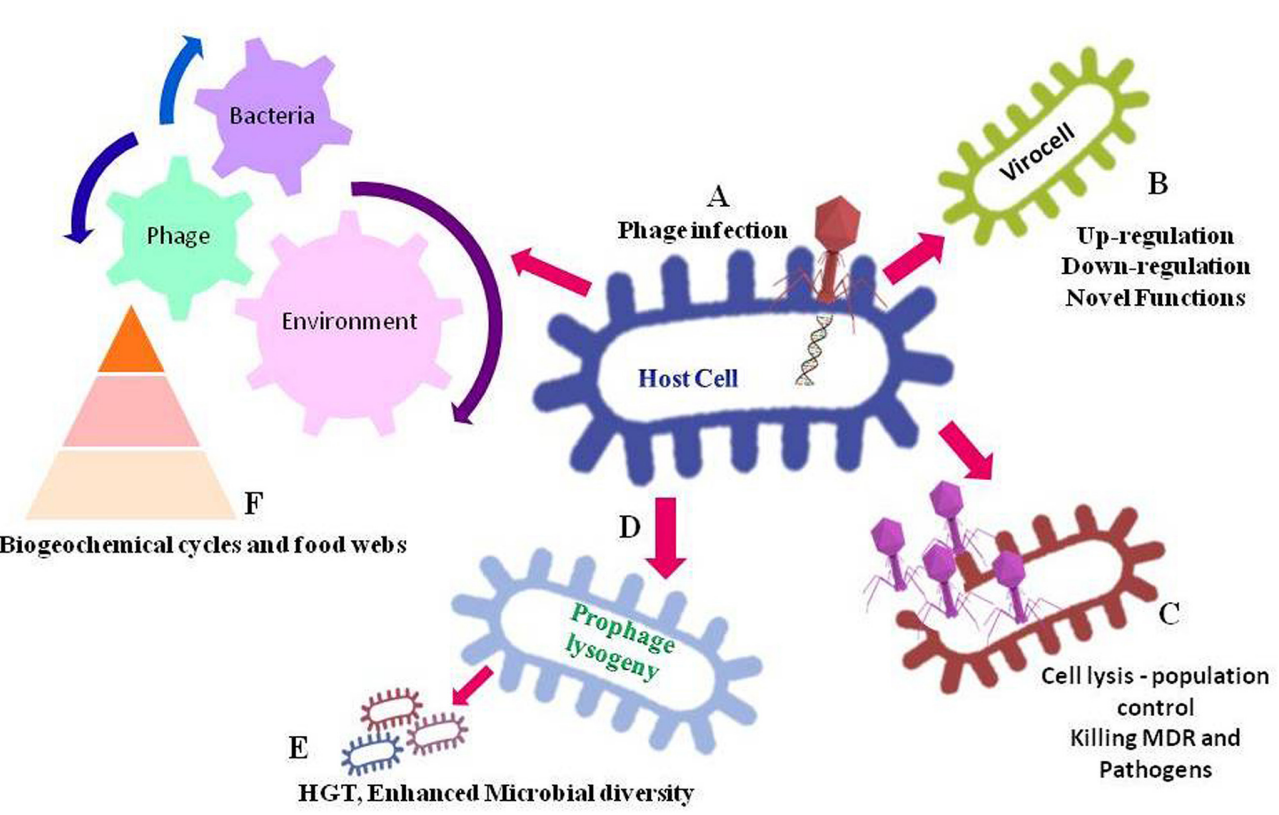

FIGURE 1 | Significance of bacteriophages in regulating environment. In this figure, (A) depicts infection and insertion phage DNA into the host cell. After the phage infection, the host cell may get converted into a virocell (B), containing vAMGs that leading to an altered regulation or novel functions in bacterial host cell. The phage infection leading to lytic cycle (C) results into lysing host cell hence, controlling cell population. Infected cell leading to a lysogeny cycle (D) may contain phage genome into the bacterial genome, which can lead to an increased microbial diversity because of horizontal gene transfers- HGT (E). Also, the dead debris of bacteria as a result of phage lysis enters the food-web and biogeochemical cycles (F), as a result the nutrients get re-circulated in the ecosystem.
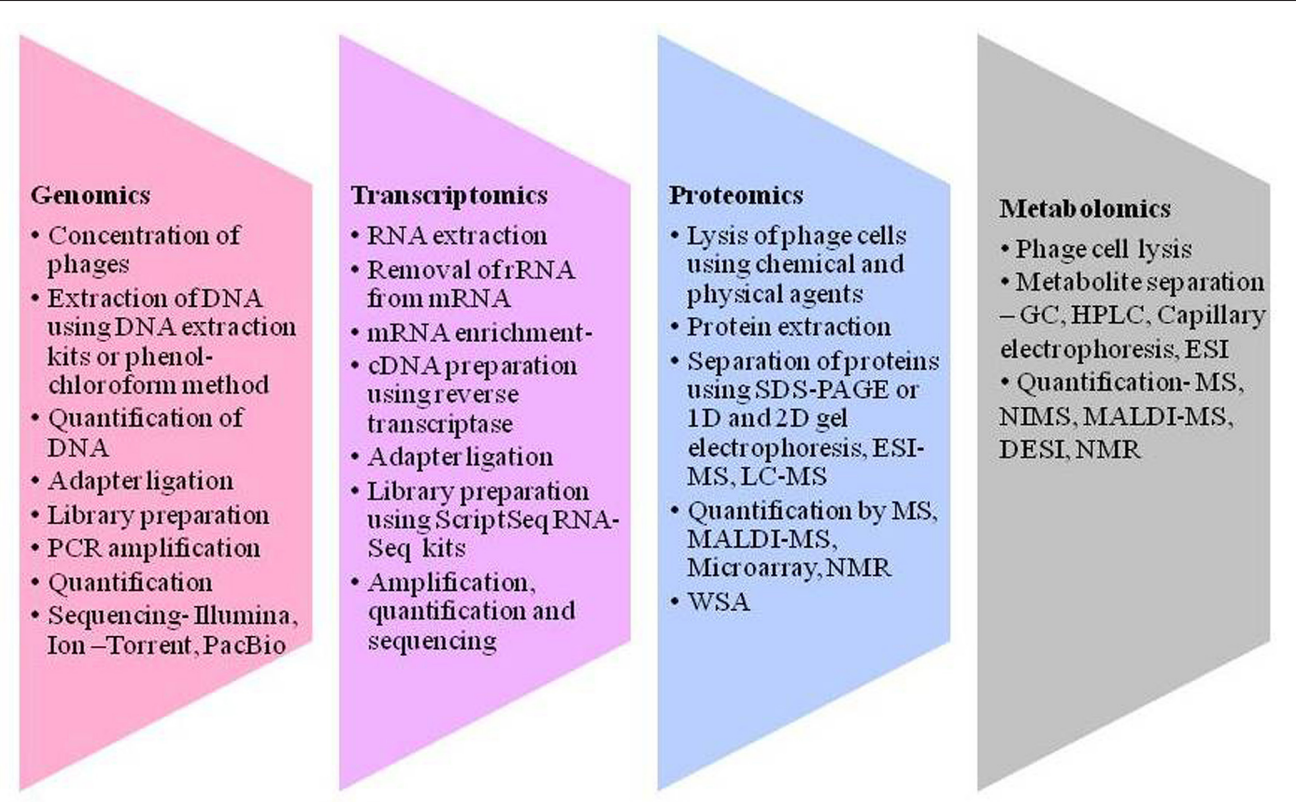

FIGURE 2 | Different techniques to gain an insight into virosphere. Genomics includes concentration of phages, DNA isolation, quantification, and sequencing Transcriptomics includes processing of RNA converting it to CDNA and sequencing. Proteomics encompasses protein extraction, separation and quantification using several tools like sodium dodecyl sulfate-polyacrylamide gel electrophoresis (SDS-PAGE), electron spray ionization -mass spectroscopy (ESI-MS), liquid chromatography-mass spectrometry (LC-MS), matrix-assisted laser ionization and deionization (MALDI)-MS and nuclear magnetic resonance (NMR), and Whole phage shotgun analysis (WSA). Metabolomics refers to metabolite extraction separation and quantification in a given time and different metabolites can be analysis using different tools like nanostructure initiator MS (NIMS) and desorption electron spray ionization (DESI) for the understanding of bacteriophage and its interactions. 
solicited to confer the claims of omics approach in phage research (Table 1).

\section{APPLICATION OF GENOMICS TO REVEAL PHAGE DIVERSITY}

Owing to the insufficiency of viral database, there is more than 90\% viral dark matter (Hurwitz et al., 2013, 2015). Additionally, the absence of a biomarker gene among phages leads to sequence the whole phage genome for its understanding (Thurber et al., 2009). The genomics of phages would elucidate the genetic composition and putative functional role in the environment. Phage metagenomics would furthermore assist in determining the diversity of phages in a community and reveal novel genes demonstrating phages to be the most diverse beings on the globe (Edwards and Rohwer, 2005). Subsequently, interpretation of functional channels of bacterial viruses would illuminate hostphage interactions (Brum et al., 2015).

A typical genomic experiment begins with isolation of genomic DNA of virus particles (Figure 3). The primary step is filtration of the sample through $0.22 \mu \mathrm{m}$ filters for elimination of bacterial constituents and other contaminations. Samples are then concentrated by ultracentrifugation or polyethylene glycol precipitation (Helms et al., 1985) and subjected to DNase and RNase treatments to exclude residual genomic material from any contaminant bacteria that may pass through $0.22 \mu \mathrm{m}$ filter. This treated sample would include only virus particles which can be cleaved and their genome can be extracted using kits or standard methods (Adhikary et al., 2014). In order to examine with NGS platforms, DNA is fragmented, ends are repaired and are ligated with adaptors (Holmfeldt et al., 2013). Finally, fragmented DNA library is cleaned and amplified through PCR as well as is quantified and sequenced. Several sequencing platforms are available such as Ion Torrent, Illumina, PacBio which are preferred as per the requirement of their read length, coverage, paired reads, insert size, accuracy, error rates, sequencing yield, run time and sequencing cost (Quail et al., 2012). To reduce chances of bacterial contamination in the library, a section of DNA is PCR amplified for $16 \mathrm{~S}$ rRNA genes, and if bands are detected, it conveys the presence of host contamination. In the instance of lesser viral DNA yields, amplification using multiple displacement amplification (MDA) can be performed, but it may generate chimeras (Yilmaz et al., 2010). Apparently, amplifications using linkers may depict impartial viromes (Duhaime et al., 2012; Hurwitz et al., 2015). The sequences acquired by sequencing are developed for data filtering and the sequence reads that passes quality check, is mapped to reference genomes or assembled de novo. If the sequence of contaminating host is furthermore present in reads even after purifying the sample, it can be distinguished by comparing reads to reference bacterial genome or $16 \mathrm{~S}$ rRNA database (Hurwitz et al., 2013). For annotation of viral genomes, a database such as NCBI non-redundant nucleotides can be used. ORFs can be determined and annotated using CyVerse (Goff et al., 2011) in the PCPipe application through the iVirus project (Hurwitz et al., 2014).
Bioinformatic tools mine enormous volume of sequence data to determine common patterns that govern microbes in an ecosystem. Viral diversity can be estimated using PHACCS toolkit (Angly et al., 2005). To decode the correlation between virus community and environmental factors, an application called Fizkin by CyVerse cyber infrastructure iVirus project selects $300 \mathrm{~K}$ reads arbitrarily from viromes and examines it using Jellyfish that generates a matrix of shared sequence counts between each virome pair. This matrix uses an input file for Bayesian network analysis resulting in a table of the relevance of environmental factor that determines the diversity of virus and a social network graph (Hurwitz et al., 2014, 2016). This will assist in ecological profiling of viral communities without requiring assembly and annotation. To elucidate sequence matches with a reference database, BLAST is regularly employed along with MG-RAST (Glass et al., 2010), MetaPhyler (Liu et al., 2010) or CARMA (Gerlach et al., 2009). For a taxonomy of viruses, MEGAN (Huson et al., 2007) software can be used whereas Hidden Markov Models, e.g., HMMER (Finn et al., 2011) are applied to match Pfam or KEGG domains. To find specific viral species present in metagenome, k-mer based algorithms such as CLARK (CLAssifier based on Reduced K-mers) (Ounit et al., 2015), USEARCH (Edgar, 2010), KRAKEN (Wood and Salzberg, 2014), and NBC (Naïve Bayes Classifier) (Rosen et al., 2011) have been applied. Sometimes, whole host genome can be observed in viromes when gene transfer agents (GTAs cluster) have filtered along with virus-like particles (Roux et al., 2013b). GTAs and sporadic contaminations can likewise be recognized using software CLARK (Ounit et al., 2015). Alignment of sequences with reference bacteria genome may reveal a prophage viral element using "recruitment plot" in the bacterial genome. Some of the bioinformatics tools adapted for prophage detection include ACLAME, Prophinder, PHAST and PhiSpy which can serve in confirming phage annotation (Akhter et al., 2012).

Along with elucidating diversity and taxonomy of phages, establishing the origin of genes (bacterial or viral) is vague. This ambiguity occur because of vAMGs which incorporates (enhancing cell metabolism in the host) into host cells or some viruses may also uptake some bacterial genes near the prophage excision site. Nevertheless, during integrating into host tRNAs, phages carry an attachment site (attP) which denote a definite match of a host tRNA gene. Example, integrase gene and an attP site (53 bp) of the Prochlorococcus phage PSS2 is a precise analogue of the host tRNA (attB, $36 \mathrm{bp}$ ) of Prochlorococcus MIT9313 (Sullivan et al., 2009). Such phages that display a putative attP site and an integrase identical to a host tRNA gene fragment are suggestive of a host-phage association (Mizuno et al., 2013). Metagenomics serves to find diversity among phages but knowledge about interaction among phage and host is relatively scanty. By analyzing the spacers in CRISPR to phage metagenomes, the bacterial host of phage (Dutilh et al., 2014) and phage-host interactions can be deduced (Anderson et al., 2011; Berg Miller et al., 2012; Edwards et al., 2016). Characterizing these constraints is requisite to develop our insight about bacterial-phage coevolution. 


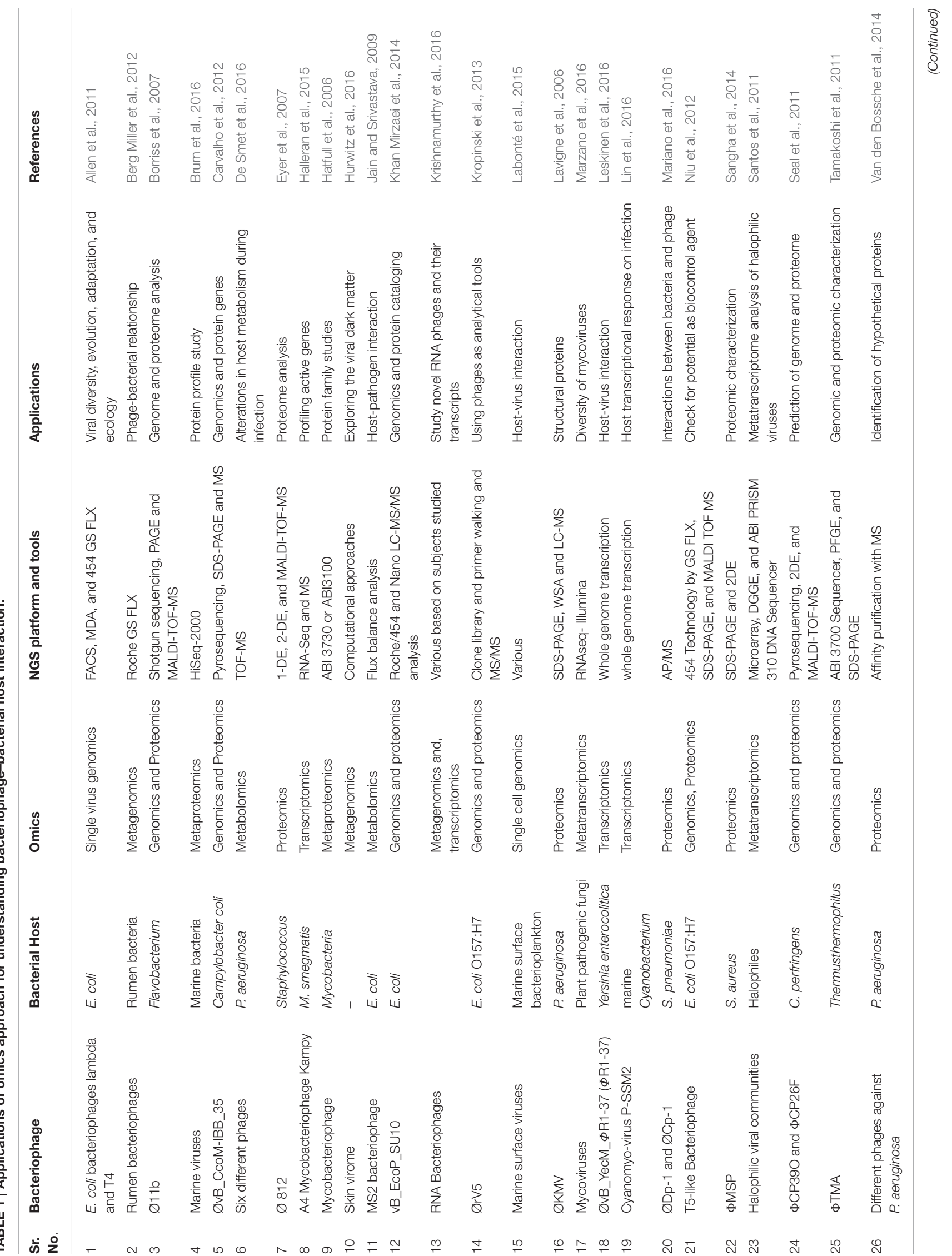




\section{Single Cell Genomics}

Apart from metagenomics, attempts have been instigated to investigate only an individual isolate in detail reinforcing our perception of the mechanisms of a specific cell rather than the influences of the entire population. Recently, single cell genomics (SCG) has been promoted to infer the phage genome which is present in or on the surface of host cells in a particular niche without culturing (Lasken and McLean, 2014) and facilitates in assuming sole genetic and metabolic profiles of uncultivable microbes. SCG helps in understanding the interplay between the phage and their host and can ascertain phage genome in a bacterial host cell. To isolate a single cell from an environment, techniques such as flow cytometry (Podar et al., 2007) and micromanipulation (Ishøy et al., 2006) have demonstrated to be advantageous. To sort a single cell precisely, a fluorescence-activated cell sorter $\left(\mathrm{FACSAria}^{\mathrm{TM}}\right)$ with a forward scatter photomultiplier tube (PMT) has been adopted to simplify accurate detection and high-resolution entry of single cell (Picot et al., 2012). Confocal laser scanning microscopy has been applied to support a single phage separation stained by fluorescent dyes lodged into agarose (Luef et al., 2009). Multiple displacement amplification (MDA) (Hosono et al., 2003) utilizes an advanced properties of phi29 DNA polymerase which intensifies a microbial genome at million-fold, sufficient for sequencing using any of the available sequencing platforms.

Interpretation of viral diversity has become easier after the expansion of single virus genomics (Allen et al., 2011) while attending one virus at a time. New computational challenges to analyze the outcomes of SCG using bioinformatics tools have emerged, reflecting the vast opportunity to figure out the in-situ phage-host communications. Several bioinformatics tools have been in practice for the classification of prophages-pathogenicity islands such as PIPS (Soares et al., 2012) and HGT- using Alien Hunter (Vernikos and Parkhill, 2006), but these tools seem weak when studying novel phages because of a deficiency of genomic sequences in the viral public database. Because of this constraint, semi-continuous and partial SCG sequences in the database do not allow the accurate identity of isolates (Kalisky and Quake, 2011). However, SCG provides cytoplasmic insights during various interactions with phages like lysogeny, lytic infections, chronic infections and unspecific attachments (Allen et al., 2011). For distinguishing between these synergies, sequences have been examined for integration of phage into the host DNA, portion of phage and host DNA was measured for the speed of single cell MDA reactions and comparisons have been made between the coverage depth of phage and host contigs (Labonté et al., 2015). Phages infecting previously unknown hosts have been discovered in the marine environment using this technique (Roux et al., 2013a, 2014; Labonté et al., 2015).

Non-specific amplification or distortions in the single genome may be a reason for the loss of data, but approximately $90 \%$ of DNA can be retrieved using SCG (Rodrigue et al., 2009). A newly developed technology called $\mathrm{Hi}$-C sequencing determines closely arranged genome sequences, like virus-bacterial host genomes within an individual cell (Beitel et al., 2014). The concept of this facility includes genome cross-linking using formaldehyde 


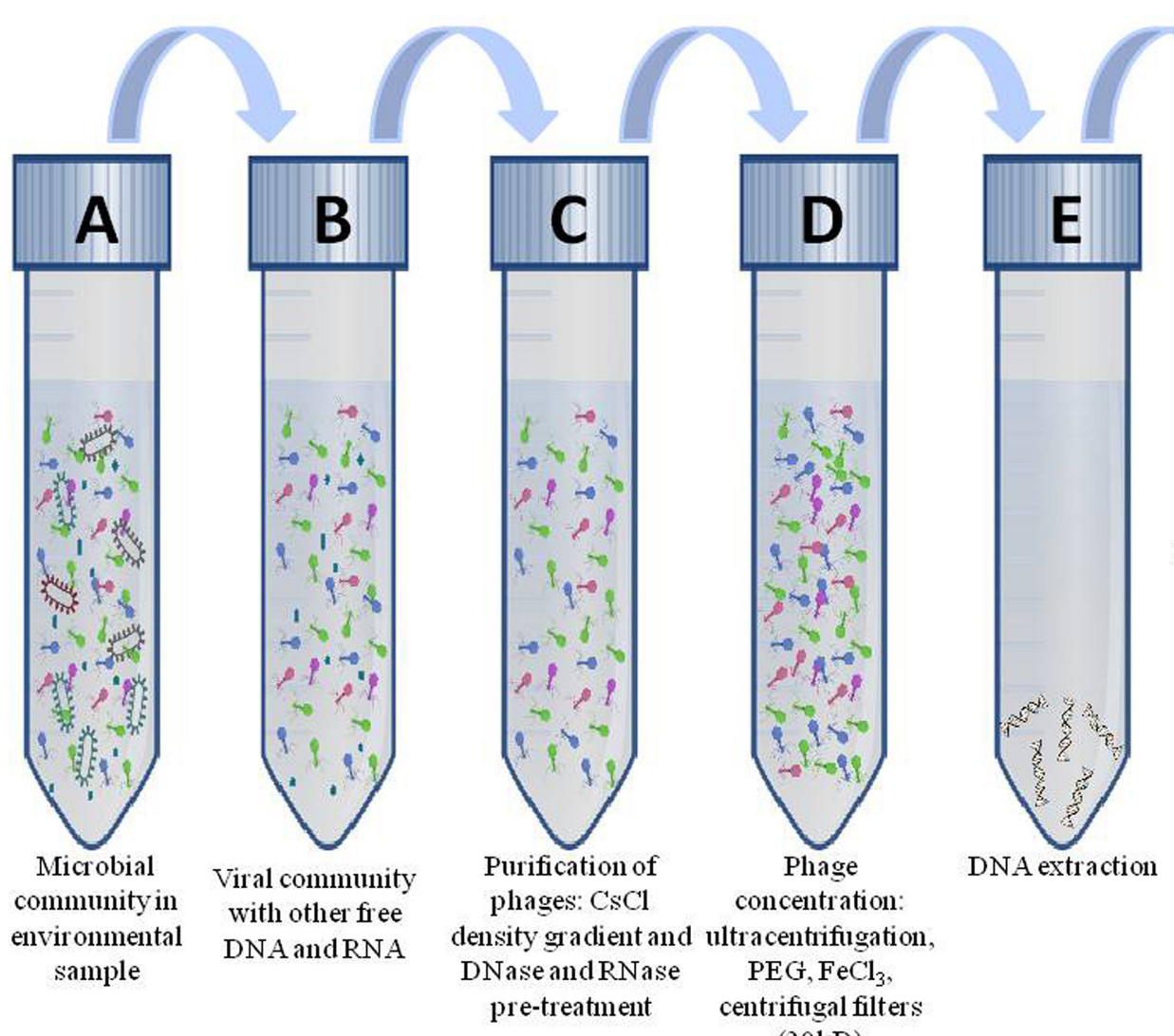

Linker

amplification or

multiple

displacement

amplification

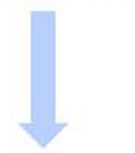

Library preparation

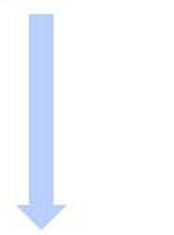

NGS: Illumina,

Ion-Torrent,

PacBio

FIGURE 3 | Workflow to study the genomic content of bacteriophages. Genomics of phages initiates by filtering phage particles from microbial community (A) through $0.22 \mu$ filter which results in (B) virus particles containing residual DNA and RNA of other microbial communities. (C) Purification of virus particles from residual DNA and RNA are removed by $\mathrm{CsCl}$ density gradient method. (D) Phage particles are concentrated using polyethylene glycol or ultra-centrifugation. (E) Extraction of viral DNA uses kits or conventional methods. The DNA is amplified and libraries are prepared and subsequently sequenced them.

and a restriction excision, followed by re-ligation of sequences using ligases in a dilute condition that support ligation events between cross-linked DNA fragments, conforming the pairs to each other that were originally in close contiguity (van Berkum et al., 2010). This technique can be adapted to phage-bacterial host communities to figure out close entity while they have been successfully operated for various microbial studies (Beitel et al., 2014; Burton et al., 2014).

Oxford Nanopore sequencing has been utilized where individual DNA molecule is directly sequenced without amplifying or labeling genome with chemical or using visualization tool to recognize the chemical label (Branton et al., 2008). Nanopore sequencing works on the principle that when a voltage is applied to a nanopore imbibed in a conducting liquid, electric current can pass through the nanopore. This electric current is highly responsive to nanopore size and shape such that indeed a single passage of DNA nucleotide pass through nanopore could affect an alteration in the current. The magnitude of current differs based on the type of nucleotides (A, T, G, or C) passing through the nanopore. Thus changing in current corresponds to the precise sequence of a DNA stretch. Viral pathogens have been examined using Nanopore technology
(Greninger et al., 2015). Concurrently, MinION sequencer has similarly been recommended which is incredibly rapid, smaller in size, produce $200 \mathrm{~kb}$ long reads with high accuracy as well as it has been used to study lambda phage DNA (Mikheyev and Tin, 2014).

Metagenomics and SCG technologies can be strongly adapted to illustrate the exact identity and diversity of phages in an environment which can guide across the dark matter of viral ecosystem (Figure 4). Along with investigating the diversity of phages in an environment, to succumb with a coherent outline of their functional aspect in an ecosystem, it becomes imperative to deduce mechanisms underlying transcriptions of phages. Hence, transcriptomic studies provide knowledge about functions of active genes in given condition.

\section{EMPLOYING TRANSCRIPTOMICS TO STUDY ACTIVE PHAGE FUNCTION}

Transcriptomics provides a measure to investigate the active microorganisms within a community at a specific time and under a definite array of conditions. Study of the transcriptome 


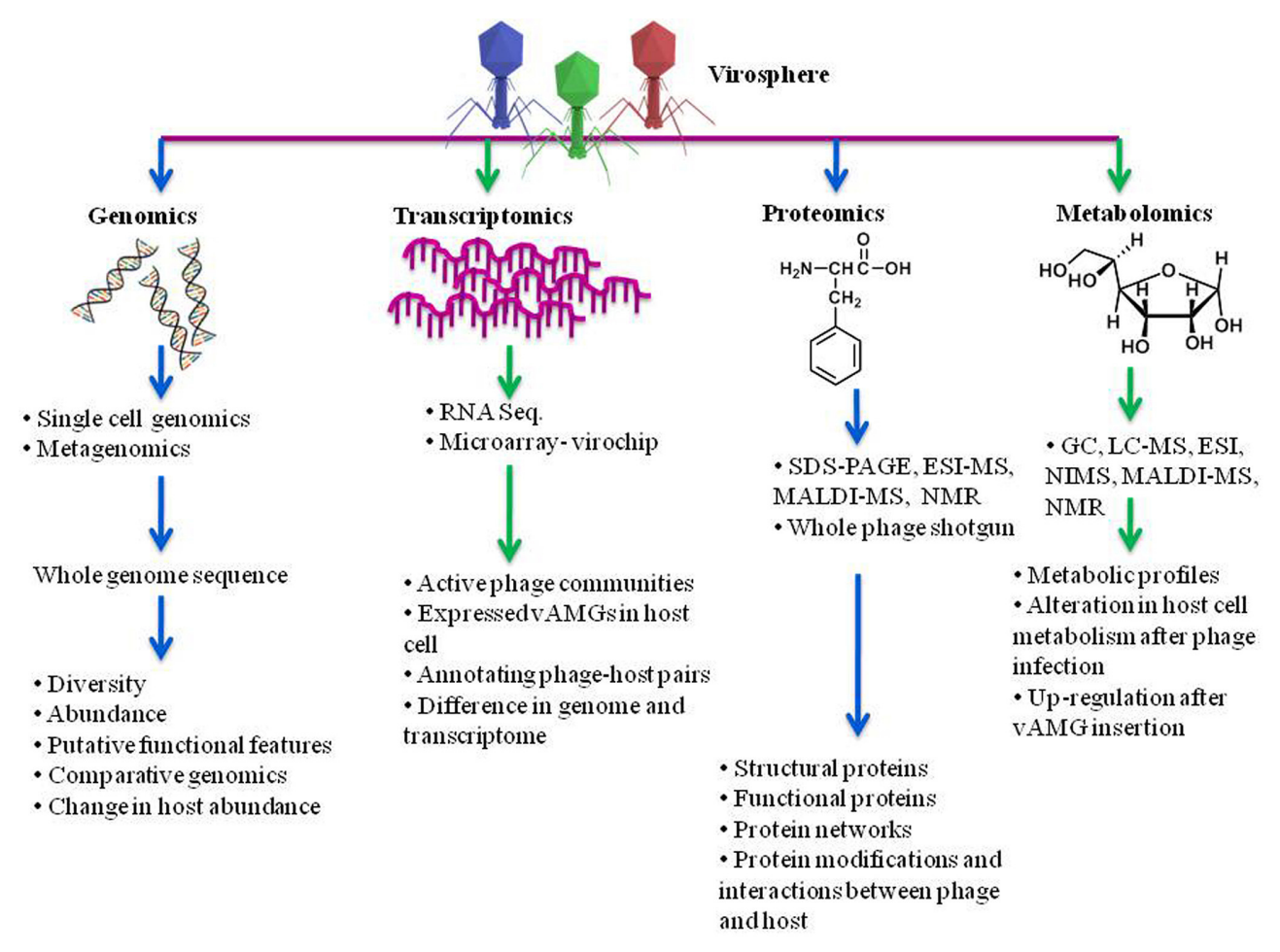

FIGURE 4 | Understanding phage diversity, community interactions and chemical profiles using meta-omics approach. Genomics elucidates the phage diversity, abundance, probable functional features while transcriptomics gives an insight about the actively expressed genes in a community. Proteomics suggests the phage structural proteins, its functions and the proteins responsible for interaction between phage and host. Metabolomics advocates the metabolites produced by hosts in presence and absence of phage infection, alterations in regulation and metabolic profiles after infection. SDS-PAGE, sodium dodecyl sulfate-polyacrylamide gel electrophoresis; ESI-MS, electron spray ionization-mass spectroscopy; LC-MS, liquid chromatography-mass spectrometry; MALDI-MS, matrix-assisted laser ionization and deionization; NMR, nuclear magnetic resonance; NIMS, nanostructure initiator MS.

is critical to analyze molecular constituent of phages and to understand genome function during a distinct period or situation such as development or infection state. The principle objectives of transcriptomics include recording transcripts of all species including mRNAs, non-coding RNAs and small RNAs, to estimate transcriptional organization of genes in terms of $5^{\prime}$ end and $3^{\prime}$ end, gene splicing and post-transcriptional modification as well as to demonstrate varying activity of each gene under different conditions (Bikel et al., 2015). Several technologies have been developed to inspect and determine transcriptomes, such as DNA hybridization technique, DNA microarray, cDNA-amplified fragment length polymorphism (cDNA-AFLP), expressed sequence tag (EST) sequencing, serial analysis of gene expression (SAGE), massive parallel signature sequencing (MPSS), and RNA-seq (Mutz et al., 2013). DNA hybridization employs fluorescently labeled cDNA to hybridize with DNA templates on microarray chips. However, this tool possesses some reserves as it relies on the hitherto studied genome sequences, high background levels for cross-hybridization and a smaller detection range. Phage meta-transcriptomics may present few difficulties as phages are incredibly diverse and their database is considerably less. Also, the availability of RNA, especially mRNA may be in a rather less volume because of inactive phase when phage is not in association with bacterial hosts. Thus, this may lead to challenges in isolating and enriching mRNA for sequencing.

A typical transcriptomics analysis using NGS includes isolation of the total RNA from the virus particles, depending on the RNA to be sequenced (mRNA, lincRNA or microRNA). Initially, the bacterial fractions are separated and purified from the phage particles. DNase and RNase treatments are administered to filter phage particles from any free DNA or RNA of bacteria. The RNA is thus extracted from virus particle using RNA extraction kits such as RNeasy mini kit. Selective elimination of rRNAs can be achieved using rRNA removing kits or using probes complementary to the rRNA region that is attached to magnetic beads. The mRNA can be enriched by magnetic bead capture method of rRNA, preferential polyadenylation of mRNA or preferential digestion of rRNA through enzymes. The cDNA are synthesized using random hexamers or oligo (dT) primers or priming with poly dT primers after polyadenylation. For amplification, RNA polymerase (Ozsolak and Milos, 2011) or MDA (Gonzalez et al., 2005) or emulsion PCR is/are performed (Tang et al., 2009). The $5^{\prime}$ and/or $3^{\prime}$ ends of the cDNA are then repaired along with adapter ligation, following library cleanup, amplification, quantification and sequencing of the library. Single-end or paired-end libraries can be prepared using kits like ScriptSeq 
RNA-Seq library preparation kit (Illumina, San Diego, CA) and can be sequenced on platforms such as Illumina HiSeq2500. Sometimes, conversion of RNA into cDNA introduces bias into the quantification of transcripts, thus a semi-direct sequencing of RNA by-passing the synthesis of cDNA has been established (Hickman et al., 2013).

The bioinformatics analysis of raw data retrieved by transcriptome sequencing uses reference genes and genomes to map against the raw reads or performing a de novo assembly for unreported transcriptomes. Mapping of transcripts against reference genome would confer taxonomy and function of active phages. Mapping the active functional pathways would expound the up-regulated, down-regulated or unaffected genes of phage during development or infection cycle. The same can be advised for the bacterial host during infection by a phage. The transcriptome reads which are short can be assembled de novo using several softwares such as Trinity. Efficiency and sensitivity of the software are exceptionally promising in procuring fulllength transcripts (Ghaffari et al., 2014). The assembled contigs that are obtained by de novo or reference-based assembly can be equated with the NCBI viral reference amino acid sequence database using USEARCH (Edgar, 2010). Moreover, the virus annotated hits can be compared with NCBI non-redundant database using BLASTX. Bowtei software can be used to calculate sequence read number and coverage depth (Langmead et al., 2009). Alignment of reads can be prepared using software called MUSCLE (Edgar, 2004) and for constructing neighbor-joining tree, MEGA software can be employed as uses for the bacterial analyses (Tamura et al., 2013).

Several phage meta-transcriptomics studies have been conducted in an attempt to analyze active phage communities. Studies have revealed the effectiveness of phage metagenome for constructing templates in the microarray (Virochip) to annotate and identify the sample (Santos et al., 2011). The total RNA extracted from the sample can be converted to cDNA, labeled and allowed to hybridize with the virochip (Santos et al., 2012). A combination of metagenomics and meta-transcriptomics study would specifically determine active phages in an environment in which phage transcripts may vary as compared to their genomic abundance (Lim et al., 2013). There can be a case when a particular set of family of genes remain less abundant in metagenomic analyses whilst those genes may be remarkably active in meta-transcriptomics dataset and/or vice versa (Franzosa et al., 2014). This insinuates that performing only a metagenomic study may not be a perfect snapshot of functional active genes in a metagenome. To overcome the tedious isolation of viral mRNA from total mRNA, SCG can be conducted along with microarrays to designate the phage-host systems without cultivating them (Santos I. M. et al., 2015). In another study, phage-host pairs have been investigated in which a fosmid viral metagenomic library was constructed and immobilized on microarray "virochip," along with them. The genomes of uncultured bacterial host cells can be sorted by fluorescence-activated cell sorting (FACS) followed by amplification via MDA. Single host cells were hybridized on virochip, and the host cells and immobilized phages with positive results were sequenced (Martínez-Garcia et al., 2014).
With this new technique, advancements toward the discovery of phage-host interactions arise in current decade (Santos F. et al., 2015). Moreover, meta-transcriptomics based enzyme discovery from phages can assist in utilizing novel enzymes with specific enzymatic characteristics for the industries and scientific communities (Schoenfeld et al., 2010).

Transcriptomics can be employed to analyze the influencing of a phage on the bacterial host after the phage infection. One such response includes induction of Shiga toxin production and acid resistance in E. coli by Shiga toxigenic phages (VesesGarcia et al., 2015). Studies confirm the fact that host genes get differentially expressed after the phage infection such as a phage "PaP3" had a down regulatory impact on host transcriptional regulators and it proved early genes of phage affected strongly by regulation of hosts (Zhao et al., 2016). This feature of phages can be promoted for formulating a phage therapy. Transcriptomics studies of phage during infection of the host can serve an insight of sequence of transcriptional events, such as initial phase consisting of gene metabolism, DNA synthesis, and regulation genes, is accompanied by a prolonged phase of structural and lysis genes (Halleran et al., 2015). These views can yield information about vAMGs which alters metabolic functions of bacterial host after phage infection. During late phase of phage infection, several up-regulating mechanisms have been observed in bacterial gene expression including stress response and stability of membranes (Leskinen et al., 2016). Additionally, enrichment of ATP synthase and ribosomal protein genes have been revealed during phage infection of phosphorous starved Cyanobacterium host (Lin et al., 2016). With further advancement and a few drawbacks, transcriptomics gives an insight of the phage-host interactions and evaluates the regulatory mechanism in bacterial hosts by phage and/or vice versa (effect of host interactions on phage regulation) which are noteworthy for developing phage therapy and comprehend novel phage antimicrobial compounds.

\section{UNDERSTANDING THE PROTEOMIC PROFILE OF PHAGES}

A proteome can be represented as a set of all expressed proteins in a cell, tissue or an organism (Theodorescu and Mischak, 2007). Proteomics is a methodology for the characterization of genetic data in a cell or an organism via protein pathways and networks (Petricoin et al., 2002) and for distinguishing the functional implication of proteins (Vlahou and Fountoulakis, 2005). It focuses at cataloging protein expression profiles at a specific period, in a definite location of the cell and as a response to foreign stimulations. It is applied to design a plot of protein networks which can be used to demonstrate interaction among protein in an organism (Corpillo et al., 2004). It provides an estimate of occurrence, quantity and modified state of proteins in an environment in a significant-throughput method.

Genome and transcriptome analysis evaluate the indirect functional profile of a cell or a community whereas proteomic reveal a direct estimate of functional activity of a cell (Schwanhäusser et al., 2011). Abundance profiles of proteins 
can be plotted using comparative metaproteomics, while the reduction or increase in the quantity of some proteins may signify a distinct purpose in an organism or during particular situations of phage infection on the bacterial host (Sangha et al., 2014). The post-infection protein expression changes can be classified as (1) function which alters rapidly on phage-infection, but can get reverted back (2) variations that develop gradually and persist consistent or cannot revert back, and (3) alterations that appear abruptly and are maintained for a longer term.

Developments in next generation tools have drastically enhanced quantification and identification of proteins (Schleicher and Wieland, 1978). The proteomic analysis commences with phage concentration accompanied by lysing phage using physical and chemical agents, consequently releasing phage proteins (Figure 2). The concentration of proteins can be measured using Bradford's method (Bradford, 1976) or can be denatured using urea (Lavigne et al., 2006) or can be digested by trypsin (Borriss et al., 2007). Several approaches and facilities have been in practice for proteomic studies (Chandramouli and Qian, 2009), however, employing some tools such as a mass spectrometer (MS) and protein-chips (microarray) have significantly contributed in the field (Horgan and Kenny, 2011). Proteins have earlier been detected and quantified using enzyme-linked immunosorbent assay (ELISA) and Western blot where proteins were initially separated by sodium dodecyl sulfate-polyacrylamide gel electrophoresis (SDS-PAGE) (Lavigne et al., 2006). Studies have been performed to understand phage proteins using MS after separating by 1D and 2D PAGE (Clement et al., 2013). Additionally, massspectrometry-based techniques such as matrix-assisted laser desorption/ionization (MALDI-MS) (Borriss et al., 2007) and electron spray ionization (ESI) (Carvalho et al., 2012) have been established for analyzing various proteins of phages. Recently, fluorescence 2D differential gel electrophoresis has been employed to distinguish between amounts of human lymph and plasma proteins (Clement et al., 2013). Structural proteomics can interpret the structure of proteins thereby determining the functions of novel genes. Lavigne et al. (2006) described structural proteome of phiKMV, a lytic bacteriophage of Pseudomonas aeruginosa using SDS-PAGE, LC-ESI-MS/MS, and GC-MS. Nuclear magnetic resonance (NMR) (Horgan and Kenny, 2011) and X-ray crystallography (Drulis-Kawa et al., 2012) can be employed to investigate the interaction between phage-binding protein and receptor site on the bacterial host (Sundell and Ivarsson, 2014).

Protein analysis using MS requires a prior separation of the sample either by 2D-gel electrophoresis (Renesto et al., 2006) or isotope-coded affinity tag (ICAT) labeling (Weston and Hood, 2004), accompanied by digestion into peptides and separating peptides using LC. Microarrays can be applied for assorting protein interaction with DNA, protein or ligands. Protein microarray technique can be exploited in the analytical study to check for presence/absence of a distinct protein in a sample (biomarker detection during phage infections) or for defining function (Uzoma and Zhu, 2013). When phage proteins are immobilized on a microarray chip, it can be applied to probe for complementary bacterial host receptors that bind with phage recognition proteins (Santos F. et al., 2015). Reverse-phase protein microarray can serve as a comparative protein profile in case of phage-infected and uninfected bacterial host (Haider and Pal, 2013). Thus, correlative examination of proteome and genome provide an interpretation of the post-translational modifications.

Functional identification of hypothetical phage proteins is performed using MS analysis after affinity purification of host protein mixtures (Van den Bossche et al., 2014). MS/MS spectra can be interpreted using SEQUEST (http://fields.scripps.edu/sequest/) or Mascot (Matrix Sciences) and classifying using DTASelect and Contrast softwares (Tabb et al., 2002). Proteomic phage display techniques are similarly employed to identify target proteins and consensus motifs (Sundell and Ivarsson, 2014). Whole phage shotgun analysis (WSA) is a recently developed technique for protein analysis using NGS platform. It is a culture-independent technique which offers annotation of proteins associated with phages. WSA combines all structural proteins separated on the basis of mass and charge before identification (Lavigne et al., 2006). After separation, the data can be annotated to open reading frames (ORFs) by aligning with reference protein sequences using BLASTP. HHpred is another tool for assigning the protein structure (Hildebrand et al., 2009). The function and evolution of identified proteins can be determined by program COGnitor (www.ncbi.nlm.nih.gov/COG) and InterProScan to find conserved domains (Eyer et al., 2007). When a predicted protein does not match along known proteins from the database, protein clustering can be developed for the comparative analyses to assess the protein diversity (Hurwitz et al., 2013; Brum et al., 2016). Some software can extract the data from MS and microarray and decipher protein identification using databases such as UniProt (http://www.uniprot.org/), PROSITE (http://prosite.expasy.org/), Pfam, Conserved Domain and PDB databases. Thus, with an advent in high-throughput proteomic technology, analytical tools, bioinformatics software and database, research on proteins have emerged as an easy task to elucidate protein matter in an environment.

\section{CATALOGING THE METABOLOME OF VIROSPHERE}

The breakdown products of metabolism or intermediates involved in the process of metabolism are termed as metabolites. Metabolites can be (1) primary- which are precisely involved in process of metabolism or (2) secondary- which may not directly take part in the growth of an organism. The metabolome of an organism corresponds to a set of metabolites including hormones, intermediates, signaling and secondary molecules in a particular cell, tissue, organ or an organism (Griffin and Vidal-Puig, 2008; Jordan et al., 2009). To explain the physiology of a particular cell, the study of metabolites is very substantial as every cell possesses a specific metabolic catalog which can influence the accurate implication of function of a cell or an organism (Nicholson and Wilson, 2003; Zhang et al., 2016). These are results of gene transcriptional and 
translational mechanisms which remain exceptionally complex, hence variations in metabolites intensify as compared to variations among transcriptome and proteome.

Various approaches have been established for separation and detection of metabolites, chiefly when metabolites are of higher molecular mass. The segregations of metabolites can be carried out using gas chromatography (GC) and high performance liquid chromatography (HPLC), capillary electrophoresis, electron spray ionization (ESI) accompanied by GC, atmospheric-pressure chemical ionization (APCI) on the ground of characteristics of metabolite to be processed (Alonso et al., 2015). Detection of separated metabolites have furthermore been attainable by using nanostructure-initiator MS (NIMS), MALDI-MS, secondary ion mass spectrometry (SIMS), desorption electron spray ionization (DESI), and NMR (Drexler et al., 2007; Cornett et al., 2008; Wiseman et al., 2008; Greer et al., 2011). Statistical tools are additionally applicable for the evaluation of elicited data such as XCMS (Patti et al., 2013), MZmine (Katajamaa et al., 2006), MetAlign (Lommen, 2009), MathDAMP (Baran et al., 2006), and LCMStats ${ }^{1}$ (Gahlaut et al., 2013). The metabolic database is available in form of METLIN (Smith et al., 2005).

Metabolomics would serve in interpreting the significance of active phage community on the environment in real time. Based on distinct phases of the phage infection or metabolic profile of the host infected with a phage, the gene markers can be inferred. The modification in host-cell metabolism by phageencoded genes (vAMGs) into the host genome, is described as a virocell amendment (Rosenwasser et al., 2016). Studying highly specific metabolic profiles of a virocell can improve in interpreting metabolic profile of vAMGs. Such comparisons were conducted to recognize host-viral interactions (Vardi et al., 2009, 2012; Fulton et al., 2014). Metabolomic analysis of phage interprets the influence of the vAMGs which is responsible for enhancing nucleotide biosynthesis (De Smet et al., 2016) via degrading host macromolecules such as DNA through catabolic pathways. The vAMGs encoded nucleases can generally degrade host DNA and encoded triglyceride lipase can degrade host triacylglycerols which yield energy and ultimately engages in the the formation of virus membrane (Malitsky et al., 2016). Example, ceramidase in Mimivirus helps in the catabolism of sphingolipids (Arslan et al., 2011). Thus, the vAMGs develop the metabolic potential of virocell through triggering novel enzymes which were not present in host machinery prior to phage infection (DeAngelis et al., 1997; Graves et al., 1999). The vAMGs can serve as a shunt between phage and their host by imparting several functional genes from one another especially

\footnotetext{
${ }^{1}$ Lcmstats: LCMStats: an [R (programming language)] package for detailed analysis of LCMS data. http://sourceforge.net/projects/lcmstats.html.
}

assisting during stress conditions (Rosenwasser et al., 2016). These mechanisms illustrate unique attributes of gene products of phage that can mediate dynamics phage-host interaction, as an effect, shaping the microbial communities in an environment. Thus, biochemical composition and metabolic profile of bacterial hosts are greatly governed by phages and released metabolites in the environment influence the microbial food web (Miki et al., 2008). Cataloging the metabolome of phages can elucidate special phage-derived metabolites which usually act as decision making between lytic or lysogenic lifecycle in virocell. Study of metagenomic and metabolomic profiles can simultaneously determine whether the metabolites are encoded by the phage or the host. Furthermore, metabolic profiles of phage can aid in tracing a novel biomarker to recognize the nutrient source in biogeochemical cycles. Thus, the advents in the omics approaches utilizing NGS techniques bear a tremendous potential in exploring virosphere and thus the microbial world.

\section{CONCLUSIONS}

Advancements in the field of NGS have facilitated the discoveries on the verge of a revolution in the course of microbial research. There has been a tremendous microbial data generated about the microbes present on Earth and their diversity and functional roles in regulating the ecosystem. Progress in interpreting the phage diversity and functions as well as the interactions among phages and their hosts are promising using the "omics" concepts. This would illuminate the function of phages in regulating microbial diversity by HGTs, governing the biogeochemical cycles, host population controls and determining the novel biomarkers. NGS will also nurture the upcoming phage therapy research for limiting MDR pathogens. With strong prospects in the field and developments in phage database, "omics" approach is witnessing a remarkable motive for a transformation in the yet uncultivable microbial research.

\section{AUTHOR CONTRIBUTIONS}

$\mathrm{KP}, \mathrm{PD}$, and RS conceived and designed the work. KP, SG, and RS wrote the manuscript. PD, RK, and RS carefully checked the manuscript and corrected. All of the authors contributed to the discussion and approved the final manuscript.

\section{ACKNOWLEDGMENTS}

The authors are thankful to Agharkar Research Institute, John Innes Center and Saurashtra University for support and encouragement.

\section{REFERENCES}

Ackermann, H. W. (2009). Phage classification and characterization. Methods Mol. Biol. 501, 127-140. doi: 10.1007/978-1-60327-164-6_13

Adhikary, A. K., Hanaoka, N., and Fujimoto, T. (2014). Simple and cost-effective restriction endonuclease analysis of human adenoviruses. Biomed. Res. Int. 2014:363790. doi: 10.1155/2014/ 363790 
Akhter, S., Aziz, R. K., and Edwards, R. A. (2012). PhiSpy: a novel algorithm for finding prophages in bacterial genomes that combines similarity- and composition-based strategies. Nucleic Acids Res. 40:e126. doi: 10.1093/nar/gks406

Allen, L. Z., Ishoey, T., Novotny, M. A., McLean, J. S., Lasken, R. S., and Williamson, S. J. (2011). Single virus genomics: a new tool for virus discovery. PLoS ONE 6:e17722. doi: 10.1371/journal.pone.0017722

Alonso, A., Marsal, S., and Julia, A. (2015). Analytical methods in untargeted metabolomics: state of the art in 2015. Front. Bioeng. Biotechnol. 3:23. doi: 10.3389/fbioe.2015.00023

Anderson, R. E., Brazelton, W. J., and Baross, J. A. (2011). Using CRISPRs as a metagenomic tool to identify microbial hosts of a diffuse flow hydrothermal vent viral assemblage. FEMS Microbiol. Ecol. 77, 120-133. doi: 10.1111/j.1574-6941.2011.01090.x

Angly, F., Rodriguez-Brito, B., Bangor, D., McNairnie, P., Breitbart, M., Salamon, P., et al. (2005). PHACCS, an online tool for estimating the structure and diversity of uncultured viral communities using metagenomic information. BMC Bioinformatics 6:41. doi: 10.1186/1471-2105-6-41

Apel, K., and Hirt, H. (2004). Reactive oxygen species: metabolism, oxidative stress, and signal transduction. Annu. Rev. Plant Biol. 55, 373-399. doi: 10.1146/annurev.arplant.55.031903.141701

Arslan, D., Legendre, M., Seltzer, V., Abergel, C., and Claverie, J. M. (2011). Distant Mimivirus relative with a larger genome highlights the fundamental features of Megaviridae. Proc. Natl. Acad. Sci. U.S.A. 108, 17486-17491. doi: 10.1073/pnas.1110889108

Baran, R., Kochi, H., Saito, N., Suematsu, M., Soga, T., Nishioka, T., et al. (2006). MathDAMP: a package for differential analysis of metabolite profiles. $B M C$ Bioinformatics 7:530. doi: 10.1186/1471-2105-7-530

Beitel, C. W., Froenicke, L., Lang, J. M., Korf, I. F., Michelmore, R. W., Eisen, J. A., et al. (2014). Strain- and plasmid-level deconvolution of a synthetic metagenome by sequencing proximity ligation products. PeerJ 2:e415. doi: $10.7717 /$ peer. 415

Berg Miller, M. E., Yeoman, C. J., Chia, N., Tringe, S. G., Angly, F. E., Edwards, R. A., et al. (2012). Phage-bacteria relationships and CRISPR elements revealed by a metagenomic survey of the rumen microbiome. Environ. Microbiol. 14, 207-227. doi: 10.1111/j.1462-2920.2011.02593.x

Bertani, G. (1951). Studies on lysogenesis. I. The mode of phage liberation by lysogenic Escherichia coli. J. Bacteriol. 62, 293-300.

Bikel, S., Valdez-Lara, A., Cornejo-Granados, F., Rico, K., Canizales-Quinteros, S., Soberon, X., et al. (2015). Combining metagenomics, metatranscriptomics and viromics to explore novel microbial interactions: towards a systemslevel understanding of human microbiome. Comput. Struct. Biotechnol. J. 13, 390-401. doi: 10.1016/j.csbj.2015.06.001

Borriss, M., Lombardot, T., Glockner, F. O., Becher, D., Albrecht, D., and Schweder, T. (2007). Genome and proteome characterization of the psychrophilic Flavobacterium bacteriophage 11b. Extremophiles 11, 95-104. doi: 10.1007/s00792-006-0014-5

Bradford, M. M. (1976). A rapid and sensitive method for the quantitation of microgram quantities of protein utilizing the principle of proteindye binding. Anal. Biochem. 72, 248-254. doi: 10.1016/0003-2697(76) 90527-3

Branton, D., Deamer, D. W., Marziali, A., Bayley, H., Benner, S. A., Butler, T., et al. (2008). The potential and challenges of nanopore sequencing. Nat. Biotechnol. 26, 1146-1153. doi: 10.1038/nbt.1495

Breitbart, M., Felts, B., Kelley, S., Mahaffy, J. M., Nulton, J., Salamon, P., et al. (2004). Diversity and population structure of a near-shore marine-sediment viral community. Proc. Biol. Sci. 271, 565-574. doi: 10.1098/rspb.2003.2628

Brum, J. R., Ignacio-Espinoza, J. C., Kim, E. H., Trubl, G., Jones, R. M., Roux, S., et al. (2016). Illuminating structural proteins in viral "dark matter" with metaproteomics. Proc. Natl. Acad. Sci. U.S.A. 113, 2436-2441. doi: $10.1073 /$ pnas.1525139113

Brum, J. R., Ignacio-Espinoza, J. C., Roux, S., Doulcier, G., Acinas, S. G., Alberti, A., et al. (2015). Ocean plankton. Patterns and ecological drivers of ocean viral communities. Science 348:1261498. doi: 10.1126/science.1261498

Brüssow, H., Canchaya, C., and Hardt, W. D. (2004). Phages and the evolution of bacterial pathogens: from genomic rearrangements to lysogenic conversion. Microbiol. Mol. Biol. Rev. 68, 560-602. doi: 10.1128/MMBR.68.3.560602.2004
Burton, J. N., Liachko, I., Dunham, M. J., and Shendure, J. (2014). Species-level deconvolution of metagenome assemblies with $\mathrm{Hi}-\mathrm{C}$-based contact probability maps. G3 (Bethesda) 4, 1339-1346. doi: 10.1534/g3.114.011825

Carvalho, C. M., Kropinski, A. M., Lingohr, E. J., Santos, S. B., King, J., and Azeredo, J. (2012). The genome and proteome of a Campylobacter coli bacteriophage vB_CcoM-IBB_35 reveal unusual features. Virol. J. 9:35. doi: $10.1186 / 1743-422 \mathrm{x}-9-35$

Chandramouli, K., and Qian, P.-Y. (2009). Proteomics: challenges, techniques and possibilities to overcome biological sample complexity. Hum. Genomics Proteomics 2009:239204. doi: 10.4061/2009/239204

Clement, C. C., Aphkhazava, D., Nieves, E., Callaway, M., Olszewski, W., Rotzschke, O., et al. (2013). Protein expression profiles of human lymph and plasma mapped by 2D-DIGE and 1D SDS-PAGE coupled with nanoLC-ESI-MS/MS bottom-up proteomics. J. Proteomics 78, 172-187. doi: 10.1016/j.jprot.2012.11.013

Cornett, D. S., Frappier, S. L., and Caprioli, R. M. (2008). MALDI-FTICR imaging mass spectrometry of drugs and metabolites in tissue. Anal. Chem. 80, 5648-5653. doi: 10.1021/ac800617s

Corpillo, D., Gardini, G., Vaira, A. M., Basso, M., Aime, S., Accotto, G. P., et al. (2004). Proteomics as a tool to improve investigation of substantial equivalence in genetically modified organisms: the case of a virus-resistant tomato. Proteomics 4, 193-200. doi: 10.1002/pmic.200300540

Crick, F. (1970). Central dogma of molecular biology. Nature 227, 561-563. doi: $10.1038 / 227561 \mathrm{a} 0$

DeAngelis, P. L., Jing, W., Graves, M. V., Burbank, D. E., and Van Etten, J. L. (1997). Hyaluronan synthase of chlorella virus PBCV-1. Science 278, 1800-1803. doi: 10.1126/science.278.5344.1800

De Smet, J., Zimmermann, M., Kogadeeva, M., Ceyssens, P. J., Vermaelen, W., Blasdel, B., et al. (2016). High coverage metabolomics analysis reveals phagespecific alterations to Pseudomonas aeruginosa physiology during infection. ISME J. 10, 1823-1835. doi: 10.1038/ismej.2016.3

Drexler, D. M., Garrett, T. J., Cantone, J. L., Diters, R. W., Mitroka, J. G., Prieto Conaway, M. C., et al. (2007). Utility of imaging mass spectrometry (IMS) by matrix-assisted laser desorption ionization (MALDI) on an ion trap mass spectrometer in the analysis of drugs and metabolites in biological tissues. J. Pharmacol. Toxicol. Methods 55, 279-288. doi: 10.1016/j.vascn.2006. 11.004

Drulis-Kawa, Z., Majkowska-Skrobek, G., Maciejewska, B., Delattre, A. S., and Lavigne, R. (2012). Learning from bacteriophages-advantages and limitations of phage and phage-encoded protein applications. Curr. Protein Pept. Sci. 13, 699-722. doi: 10.2174/138920312804871193

Duhaime, M. B., Deng, L., Poulos, B. T., and Sullivan, M. B. (2012). Towards quantitative metagenomics of wild viruses and other ultralow concentration DNA samples: a rigorous assessment and optimization of the linker amplification method. Environ. Microbiol. 14, 2526-2537. doi: 10.1111/j.1462-2920.2012.02791.x

Dutilh, B. E., Cassman, N., McNair, K., Sanchez, S. E., Silva, G. G., Boling, L., et al. (2014). A highly abundant bacteriophage discovered in the unknown sequences of human faecal metagenomes. Nat. Commun. 5:4498. doi: $10.1038 /$ ncomms5498

Dutta, C., and Pan, A. (2002). Horizontal gene transfer and bacterial diversity. J. Biosci. 27, 27-33. doi: 10.1007/BF02703681

Eberwine, J., Sul, J. Y., Bartfai, T., and Kim, J. (2014). The promise of single-cell sequencing. Nat. Methods 11, 25-27. doi: 10.1038/nmeth.2769

Edgar, R. C. (2004). MUSCLE: multiple sequence alignment with high accuracy and high throughput. Nucleic Acids Res. 32, 1792-1797. doi: 10.1093/nar/gkh340

Edgar, R. C. (2010). Search and clustering orders of magnitude faster than BLAST. Bioinformatics 26, 2460-2461. doi: 10.1093/bioinformatics/btq461

Edwards, R. A., McNair, K., Faust, K., Raes, J., and Dutilh, B. E. (2016). Computational approaches to predict bacteriophage-host relationships. FEMS Microbiol. Rev. 40, 258-272. doi: 10.1093/femsre/fuv048

Edwards, R. A., and Rohwer, F. (2005). Viral metagenomics. Nat. Rev. Microbiol. 3, 504-510. doi: 10.1038/nrmicro1163

Eyer, L., Pantucek, R., Zdrahal, Z., Konecna, H., Kasparek, P., Ruzickova, V., et al. (2007). Structural protein analysis of the polyvalent staphylococcal bacteriophage 812. Proteomics 7, 64-72. doi: 10.1002/pmic.2006 00280 
Finn, R. D., Clements, J., and Eddy, S. R. (2011). HMMER web server: interactive sequence similarity searching. Nucleic Acids Res. 39, W29-W37. doi: 10.1093/nar/gkr367

Franzosa, E. A., Morgan, X. C., Segata, N., Waldron, L., Reyes, J., Earl, A. M., et al. (2014). Relating the metatranscriptome and metagenome of the human gut. Proc. Natl. Acad. Sci. U.S.A. 111, E2329-E2338. doi: 10.1073/pnas.13192 84111

Fulton, J. M., Fredricks, H. F., Bidle, K. D., Vardi, A., Kendrick, B. J., Ditullio, G. R., et al. (2014). Novel molecular determinants of viral susceptibility and resistance in the lipidome of Emiliania huxleyi. Environ. Microbiol. 16, 1137-1149. doi: 10.1111/1462-2920.12358

Gahlaut, A., Vikas., Dahiya, M., Gothwal, A., Kulharia, M., Chhillar, A. K., et al. (2013). Proteomics \& metabolomics: mapping biochemical regulations. Drug Invention Today 5, 321-326. doi: 10.1016/j.dit.2013. 08.007

Gerlach, W., Junemann, S., Tille, F., Goesmann, A., and Stoye, J. (2009). WebCARMA: a web application for the functional and taxonomic classification of unassembled metagenomic reads. BMC Bioinformatics 10:430. doi: 10.1186/1471-2105-10-430

Ghaffari, N., Sanchez-Flores, A., Doan, R., Garcia-Orozco, K. D., Chen, P. L., Ochoa-Leyva, A., et al. (2014). Novel transcriptome assembly and improved annotation of the whiteleg shrimp (Litopenaeus vannamei), a dominant crustacean in global seafood mariculture. Sci. Rep. 4:7081. doi: $10.1038 /$ srep07081

Glass, E. M., Wilkening, J., Wilke, A., Antonopoulos, D., and Meyer, F. (2010). Using the metagenomics RAST server (MG-RAST) for analyzing shotgun metagenomes. Cold Spring Harb. Protoc. 2010:pdb.prot5368. doi: $10.1101 /$ pdb.prot5368

Goff, S. A., Vaughn, M., McKay, S., Lyons, E., Stapleton, A. E., Gessler, D., et al. (2011). The iPlant collaborative: cyberinfrastructure for plant biology. Front. Plant Sci. 2:34. doi: 10.3389/fpls.2011.00034

Gonzalez, J. M., Portillo, M. C., and Saiz-Jimenez, C. (2005). Multiple displacement amplification as a pre-polymerase chain reaction (prePCR) to process difficult to amplify samples and low copy number sequences from natural environments. Environ. Microbiol. 7, 1024-1028. doi: 10.1111/j.1462-2920.2005.00779.x

Graves, M. V., Burbank, D. E., Roth, R., Heuser, J., Deangelis, P. L., and Van Etten, J. L. (1999). Hyaluronan synthesis in virus PBCV-1-infected chlorella-like green algae. Virology 257, 15-23. doi: 10.1006/viro.1999.9628

Greer, T., Sturm, R., and Li, L. (2011). Mass spectrometry imaging for drugs and metabolites. J. Proteomics 74, 2617-2631. doi: 10.1016/j.jprot.2011. 03.032

Greninger, A. L., Naccache, S. N., Federman, S., Yu, G., Mbala, P., Bres, V., et al. (2015). Rapid metagenomic identification of viral pathogens in clinical samples by real-time nanopore sequencing analysis. Genome Med. 7:99. doi: 10.1186/s13073-015-0220-9

Griffin, J. L., and Vidal-Puig, A. (2008). Current challenges in metabolomics for diabetes research: a vital functional genomic tool or just a ploy for gaining funding? Physiol. Genomics 34, 1-5. doi: 10.1152/physiolgenomics.00 009.2008

Haider, S., and Pal, R. (2013). Integrated analysis of transcriptomic and proteomic data. Curr. Genomics 14, 91-110. doi: 10.2174/13892029113140 20003

Halleran, A., Clamons, S., and Saha, M. (2015). Transcriptomic characterization of an infection of Mycobacterium smegmatis by the cluster a4 mycobacteriophage kampy. PLoS ONE 10:e0141100. doi: 10.1371/journal.pone. 0141100

Handelsman, J. (2004). Metagenomics: application of genomics to uncultured microorganisms. Microbiol. Mol. Biol. Rev. 68, 669-685. doi: 10.1128/MMBR.68.4.669-685.2004

Hatfull, G. F., Pedulla, M. L., Jacobs-Sera, D., Cichon, P. M., Foley, A., Ford, M. E., et al. (2006). Exploring the mycobacteriophage metaproteome: phage genomics as an educational platform. PLoS Genet. 2:e92. doi: 10.1371/journal.pgen.0020092

Helms, C., Graham, M. Y., Dutchik, J. E., and Olson, M. V. (1985). A new method for purifying lambda DNA from phage lysates. DNA 4, 39-49. doi: 10.1089/dna.1985.4.39
Hickman, S. E., Kingery, N. D., Ohsumi, T. K., Borowsky, M. L., Wang, L. C., Means, T. K., et al. (2013). The microglial sensome revealed by direct RNA sequencing. Nat. Neurosci. 16, 1896-1905. doi: 10.1038/ nn. 3554

Hildebrand, A., Remmert, M., Biegert, A., and Söding, J. (2009). Fast and accurate automatic structure prediction with HHpred. Proteins 77 (Suppl. 9), 128-132. doi: $10.1002 /$ prot.22499

Holmfeldt, K., Solonenko, N., Shah, M., Corrier, K., Riemann, L., Verberkmoes, N. C., et al. (2013). Twelve previously unknown phage genera are ubiquitous in global oceans. Proc. Natl. Acad. Sci. U.S.A. 110, 12798-12803. doi: 10.1073/pnas.1305956110

Horgan, R. P., and Kenny, L. C. (2011). 'Omic' technologies: genomics, transcriptomics, proteomics and metabolomics. J. Obstet. Gynaecol. 13, 189-195. doi: 10.1576/toag.13.3.189.27672

Hosono, S., Faruqi, A. F., Dean, F. B., Du, Y., Sun, Z., Wu, X., et al. (2003). Unbiased whole-genome amplification directly from clinical samples. Genome Res. 13, 954-964. doi: 10.1101/gr.816903

Hurwitz, B. L., Brum, J. R., and Sullivan, M. B. (2015). Depth-stratified functional and taxonomic niche specialization in the 'core' and 'flexible' Pacific Ocean virome. ISME J. 9, 472-484. doi: 10.1038/ismej.2014.143

Hurwitz, B. L., Hallam, S. J., and Sullivan, M. B. (2013). Metabolic reprogramming by viruses in the sunlit and dark ocean. Genome Biol. 14:R123. doi: 10.1186/gb-2013-14-11-r123

Hurwitz, B. L., U'ren, J. M., and Youens-Clark, K. (2016). Computational prospecting the great viral unknown. FEMS Microbiol. Lett. 363:fnw077. doi: 10.1093/femsle/fnw077

Hurwitz, B. L., Westveld, A. H., Brum, J. R., and Sullivan, M. B. (2014). Modeling ecological drivers in marine viral communities using comparative metagenomics and network analyses. Proc. Natl. Acad. Sci. U.S.A. 111, 10714-10719. doi: 10.1073/pnas.1319778111

Huson, D. H., Auch, A. F., Qi, J., and Schuster, S. C. (2007). MEGAN analysis of metagenomic data. Genome Res. 17, 377-386. doi: 10.1101/gr.5969107

Ishøy, T., Kvist, T., Westermann, P., and Ahring, B. K. (2006). An improved method for single cell isolation of prokaryotes from meso-, thermo- and hyperthermophilic environments using micromanipulation. Appl. Microbiol. Biotechnol. 69, 510-514. doi: 10.1007/s00253-005-0014-x

Jain, R., and Srivastava, R. (2009). Metabolic investigation of host/pathogen interaction using MS2-infected Escherichia coli. BMC Syst. Biol. 3:121. doi: 10.1186/1752-0509-3-121

Jordan, K. W., Nordenstam, J., Lauwers, G. Y., Rothenberger, D. A., Alavi, K., Garwood, M., et al. (2009). Metabolomic characterization of human rectal adenocarcinoma with intact tissue magnetic resonance spectroscopy. Dis. Colon Rectum 52, 520-525. doi: 10.1007/DCR.0b013e31819 $\mathrm{c} 9 \mathrm{a} 2 \mathrm{c}$

Juhala, R. J., Ford, M. E., Duda, R. L., Youlton, A., Hatfull, G. F., and Hendrix, R. W. (2000). Genomic sequences of bacteriophages HK97 and HK022: pervasive genetic mosaicism in the lambdoid bacteriophages. J. Mol. Biol. 299, 27-51. doi: $10.1006 /$ jmbi. 2000.3729

Kalisky, T., and Quake, S. R. (2011). Single-cell genomics. Nat. Methods 8, 311-314. doi: 10.1038/nmeth0411-311

Katajamaa, M., Miettinen, J., and Oresic, M. (2006). MZmine: toolbox for processing and visualization of mass spectrometry based molecular profile data. Bioinformatics 22, 634-636. doi: 10.1093/bioinformatics/btk039

Khan Mirzaei, M., Eriksson, H., Kasuga, K., Haggard-Ljungquist, E., and Nilsson, A. S. (2014). Genomic, proteomic, morphological, and phylogenetic analyses of vB_EcoP_SU10, a podoviridae phage with C3 morphology. PLoS ONE 9:e116294. doi: 10.1371/journal.pone.0116294

Krishnamurthy, S. R., Janowski, A. B., Zhao, G., Barouch, D., and Wang, D. (2016). Hyperexpansion of RNA bacteriophage diversity. PLoS Biol. 14:e1002409. doi: 10.1371/journal.pbio.1002409

Kropinski, A. M., Waddell, T., Meng, J., Franklin, K., Ackermann, H. W., Ahmed, R., et al. (2013). The host-range, genomics and proteomics of Escherichia coli O157:H7 bacteriophage rV5. Virol. J. 10:76. doi: 10.1186/1743$422 \mathrm{X}-10-76$

Labonté, J. M., Swan, B. K., Poulos, B., Luo, H., Koren, S., Hallam, S. J., et al. (2015). Single-cell genomics-based analysis of virus-host interactions in marine surface bacterioplankton. ISME J. 9, 2386-2399. doi: 10.1038/ismej.2015.48 
Langmead, B., Trapnell, C., Pop, M., and Salzberg, S. L. (2009). Ultrafast and memory-efficient alignment of short DNA sequences to the human genome. Genome Biol. 10:R25. doi: 10.1186/gb-2009-10-3-r25

Lasken, R. S., and McLean, J. S. (2014). Recent advances in genomic DNA sequencing of microbial species from single cells. Nat. Rev. Genet. 15, 577-584. doi: $10.1038 / \mathrm{nrg} 3785$

Lavigne, R., Noben, J. P., Hertveldt, K., Ceyssens, P. J., Briers, Y., Dumont, D., et al. (2006). The structural proteome of Pseudomonas aeruginosa bacteriophage phiKMV. Microbiology 152, 529-534. doi: 10.1099/mic.0.28431-0

Leskinen, K., Blasdel, B. G., Lavigne, R., and Skurnik, M. (2016). RNA-sequencing reveals the progression of phage-host interactions between phir1-37 and Yersinia enterocolitica. Viruses 8:111. doi: 10.3390/v8040111

Li, M., Wang, B., Zhang, M., Rantalainen, M., Wang, S., Zhou, H., et al. (2008). Symbiotic gut microbes modulate human metabolic phenotypes. Proc. Natl. Acad. Sci. U.S.A. 105, 2117-2122. doi: 10.1073/pnas.0712038105

Lim, Y. W., Schmieder, R., Haynes, M., Willner, D., Furlan, M., Youle, M., et al. (2013). Metagenomics and metatranscriptomics: windows on CFassociated viral and microbial communities. J. Cyst. Fibros. 12, 154-164. doi: 10.1016/j.jcf.2012.07.009

Lin, X., Ding, H., and Zeng, Q. (2016). Transcriptomic response during phage infection of a marine cyanobacterium under phosphorus-limited conditions. Environ. Microbiol. 18, 450-460. doi: 10.1111/1462-2920.13104

Liu, B., Gibbons, T., Ghodsi, M., and Pop, M. (2010). "MetaPhyler: taxonomic profiling for metagenomic sequences," in IEEE International Conference on Bioinformatics and Biomedicine (Hong-Kong: IEEE), 95-100.

Lommen, A. (2009). MetAlign: interface-driven, versatile metabolomics tool for hyphenated full-scan mass spectrometry data preprocessing. Anal. Chem. 81, 3079-3086. doi: 10.1021/ac900036d

Luef, B., Neu, T. R., and Peduzzi, P. (2009). Imaging and quantifying virus fluorescence signals on aquatic aggregates: a new method and its implication for aquatic microbial ecology. FEMS Microbiol. Ecol. 68, 372-380. doi: 10.1111/j.1574-6941.2009.00675.x

Malitsky, S., Ziv, C., Rosenwasser, S., Zheng, S., Schatz, D., Porat, Z., et al. (2016). Viral infection of the marine alga Emiliania huxleyi triggers lipidome remodeling and induces the production of highly saturated triacylglycerol. New Phytol. 210, 88-96. doi: 10.1111/nph.13852

Mariano, R., Wuchty, S., Vizoso-Pinto, M. G., Hauser, R., and Uetz, P. (2016). The interactome of Streptococcus pneumoniae and its bacteriophages show highly specific patterns of interactions among bacteria and their phages. Sci. Rep. 6:24597. doi: 10.1038/srep24597

Martínez-Garcia, M., Santos, F., Moreno-Paz, M., Parro, V., and Antón, J. (2014). Unveiling viral-host interactions within the 'microbial dark matter'. Nat. Commun. 5:4542. doi: 10.1038/ncomms5542

Marzano, S. Y., Nelson, B. D., Ajayi-Oyetunde, O., Bradley, C. A., Hughes, T. J., Hartman, G. L., et al. (2016). Identification of diverse mycoviruses through metatranscriptomics characterization of the viromes of five major fungal plant pathogens. J. Virol. 90, 6846-6863. doi: 10.1128/JVI.00357-16

Meyer, F., Paarmann, D., D'souza, M., Olson, R., Glass, E. M., Kubal, M., et al. (2008). The metagenomics RAST server-a public resource for the automatic phylogenetic and functional analysis of metagenomes. BMC Bioinformatics 9:386. doi: 10.1186/1471-2105-9-386

Mikheyev, A. S., and Tin, M. M. (2014). A first look at the Oxford Nanopore MinION sequencer. Mol. Ecol. Resour. 14, 1097-1102. doi: 10.1111/1755-0998.12324

Miki, T., Nakazawa, T., Yokokawa, T., and Nagata, T. (2008). Functional consequences of viral impacts on bacterial communities: a food-web model analysis. Freshw. Biol. 53, 1142-1153. doi: 10.1111/j.1365-2427.2007. 01934.x

Minot, S., Sinha, R., Chen, J., Li, H., Keilbaugh, S. A., Wu, G. D., et al. (2011). The human gut virome: inter-individual variation and dynamic response to diet. Genome Res. 21, 1616-1625. doi: 10.1101/gr.122705.111

Mizuno, C. M., Rodriguez-Valera, F., Kimes, N. E., and Ghai, R. (2013). Expanding the marine virosphere using metagenomics. PLoS Genet. 9:e1003987. doi: 10.1371/journal.pgen.1003987

Mutz, K. O., Heilkenbrinker, A., Lonne, M., Walter, J. G., and Stahl, F. (2013). Transcriptome analysis using next-generation sequencing. Curr. Opin. Biotechnol. 24, 22-30. doi: 10.1016/j.copbio.2012.09.004
Nicholson, J. K., and Wilson, I. D. (2003). Opinion: understanding 'global' systems biology: metabonomics and the continuum of metabolism. Nat. Rev. Drug Discov. 2, 668-676. doi: 10.1038/nrd1157

Niu, Y. D., Stanford, K., Kropinski, A. M., Ackermann, H. W., Johnson, R. P., She, Y. M., et al. (2012). Genomic, proteomic and physiological characterization of a T5-like bacteriophage for control of Shiga toxin-producing Escherichia coli O157:H7. PLoS ONE 7:e34585. doi: 10.1371/journal.pone.0034585

Ounit, R., Wanamaker, S., Close, T. J., and Lonardi, S. (2015). CLARK: fast and accurate classification of metagenomic and genomic sequences using discriminative k-mers. BMC Genomics 16:236. doi: 10.1186/s12864-015-1419-2

Ozsolak, F., and Milos, P. M. (2011). RNA sequencing: advances, challenges and opportunities. Nat. Rev. Genet. 12, 87-98. doi: 10.1038/nrg2934

Parmar, K. M., Hathi, Z. J., and Dafale, N. A. (2017). Control of multidrugresistant gene flow in the environment through bacteriophage intervention. Appl Biochem Biotechnol. 181, 1007-1029. doi: 10.1007/s12010-016-2265-7

Patti, G. J., Tautenhahn, R., Rinehart, D., Cho, K., Shriver, L. P., Manchester, M., et al. (2013). A view from above: cloud plots to visualize global metabolomic data. Anal. Chem. 85, 798-804. doi: 10.1021/ac3029745

Petricoin, E. F., Zoon, K. C., Kohn, E. C., Barrett, J. C., and Liotta, L. A. (2002). Clinical proteomics: translating benchside promise into bedside reality. Nat. Rev. Drug Discov. 1, 683-695. doi: 10.1038/nrd891

Picot, J., Guerin, C. L., Le Van Kim, C., and Boulanger, C. M. (2012). Flow cytometry: retrospective, fundamentals and recent instrumentation. Cytotechnology 64, 109-130. doi: 10.1007/s10616-011-9415-0

Podar, M., Abulencia, C. B., Walcher, M., Hutchison, D., Zengler, K., Garcia, J. A., et al. (2007). Targeted access to the genomes of low-abundance organisms in complex microbial communities. Appl. Environ. Microbiol. 73, 3205-3214. doi: 10.1128/AEM.02985-06

Prestel, E., Salamitou, S., and Dubow, M. S. (2008). An examination of the bacteriophages and bacteria of the Namib desert. J. Microbiol. 46, 364-372. doi: 10.1007/s12275-008-0007-4

Prigent, M., Leroy, M., Confalonieri, F., Dutertre, M., and Dubow, M. S. (2005). A diversity of bacteriophage forms and genomes can be isolated from the surface sands of the Sahara Desert. Extremophiles 9, 289-296. doi: 10.1007/s00792-005-0444-5

Qin, J., Li, R., Raes, J., Arumugam, M., Burgdorf, K. S., Manichanh, C., et al. (2010). A human gut microbial gene catalogue established by metagenomic sequencing. Nature 464, 59-65. doi: 10.1038/nature08821

Quail, M. A., Smith, M., Coupland, P., Otto, T. D., Harris, S. R., Connor, T. R., et al. (2012). A tale of three next generation sequencing platforms: comparison of Ion Torrent, Pacific Biosciences and Illumina MiSeq sequencers. BMC Genomics 13:341. doi: 10.1186/1471-2164-13-341

Renesto, P., Abergel, C., Decloquement, P., Moinier, D., Azza, S., Ogata, H., et al. (2006). Mimivirus giant particles incorporate a large fraction of anonymous and unique gene products. J. Virol. 80, 11678-11685. doi: 10.1128/JVI.00 940-06

Rodrigue, S., Malmstrom, R. R., Berlin, A. M., Birren, B. W., Henn, M. R., and Chisholm, S. W. (2009). Whole genome amplification and de novo assembly of single bacterial cells. PLoS ONE 4:e6864. doi: 10.1371/journal.pone.0006864

Rohwer, F., and Thurber, R. V. (2009). Viruses manipulate the marine environment. Nature 459, 207-212. doi: 10.1038/nature08060

Rosen, G. L., Reichenberger, E. R., and Rosenfeld, A. M. (2011). NBC: the Naive Bayes Classification tool webserver for taxonomic classification of metagenomic reads. Bioinformatics 27, 127-129. doi: 10.1093/bioinformatics/btq619

Rosenwasser, S., Ziv, C., Creveld, S. G., and Vardi, A. (2016). Virocell metabolism: metabolic innovations during host-virus interactions in the ocean. Trends Microbiol. 24, 821-832. doi: 10.1016/j.tim.2016.06.006

Roux, S., Enault, F., Bronner, G., Vaulot, D., Forterre, P., and Krupovic, M. (2013a). Chimeric viruses blur the borders between the major groups of eukaryotic single-stranded DNA viruses. Nat. Commun. 4:2700. doi: 10.1038/ncomms3700

Roux, S., Hawley, A. K., Torres Beltran, M., Scofield, M., Schwientek, P., Stepanauskas, R., et al. (2014). Ecology and evolution of viruses infecting uncultivated SUP05 bacteria as revealed by single-cell- and meta-genomics. eLife 3:e03125. doi: 10.7554/eLife.03125

Roux, S., Krupovic, M., Debroas, D., Forterre, P., and Enault, F. (2013b). Assessment of viral community functional potential from viral metagenomes 
may be hampered by contamination with cellular sequences. Open Biol. 3:130160. doi: 10.1098/rsob.130160

Sanchez, S. E., Cuevas, D. A., Rostron, J. E., Liang, T. Y., Pivaroff, C. G., Haynes, M. R., et al. (2015). Phage phenomics: physiological approaches to characterize novel viral proteins. J. Vis. Exp. e52854. doi: 10.3791/52854

Sangha, K. K., Kumar, B. V., Agrawal, R. K., Deka, D., and Verma, R. (2014). Proteomic characterization of lytic bacteriophages of Staphylococcus aureus Isolated from Sewage Affluent of India. Int. Sch. Res. Notices 2014:265298. doi: $10.1155 / 2014 / 265298$

Santos, F., Martínez-García, M., Parro, V., and Antón, J. (2015). Microarray tools to unveil viral-microbe interactions in nature. Front. Ecol. Evol. 3:31. doi: 10.3389/fevo.2014.00031

Santos, F., Moreno-Paz, M., Meseguer, I., Lopez, C., Rossello-Mora, R., Parro, V., et al. (2011). Metatranscriptomic analysis of extremely halophilic viral communities. ISME J. 5, 1621-1633. doi: 10.1038/ismej.2011.34

Santos, F., Yarza, P., Parro, V., Meseguer, I., Rossello-Mora, R., and Anton, J. (2012). Culture-independent approaches for studying viruses from hypersaline environments. Appl. Environ. Microbiol. 78, 1635-1643. doi: 10.1128/AEM.07175-11

Santos, I. M., Da Rosa, E. A., Graf, T., Ferreira, L. G., Petry, A., Cavalheiro, F., et al. (2015). Analysis of immunological, viral, genetic, and environmental factors that might be associated with decreased susceptibility to HIV infection in serodiscordant couples in Florianopolis, Southern Brazil. AIDS Res. Hum. Retroviruses 31, 1116-1125. doi: 10.1089/aid.2015.0168

Schleicher, E., and Wieland, O. H. (1978). Evaluation of the Bradford method for protein determination in body fluids. J. Clin. Chem. Clin. Biochem. 16, 533-534.

Schoenfeld, T., Liles, M., Wommack, K. E., Polson, S. W., Godiska, R., and Mead, D. (2010). Functional viral metagenomics and the next generation of molecular tools. Trends Microbiol. 18, 20-29. doi: 10.1016/j.tim.2009.10.001

Schwanhäusser, B., Busse, D., Li, N., Dittmar, G., Schuchhardt, J., Wolf, J., et al. (2011). Global quantification of mammalian gene expression control. Nature 473, 337-342. doi: 10.1038/nature 10098

Seal, B. S., Fouts, D. E., Simmons, M., Garrish, J. K., Kuntz, R. L., Woolsey, R., et al. (2011). Clostridium perfringens bacteriophages PhiCP39O and PhiCP26F: genomic organization and proteomic analysis of the virions. Arch. Virol. 156, 25-35. doi: 10.1007/s00705-010-0812-z

Short, C. M., and Suttle, C. A. (2005). Nearly identical bacteriophage structural gene sequences are widely distributed in both marine and freshwater environments. Appl. Environ. Microbiol. 71, 480-486. doi: 10.1128/AEM.71.1.480-486.2005

Sime-Ngando, T., and Colombet, J. (2009). [Virus and prophages in aquatic ecosystems]. Can. J. Microbiol. 55, 95-109. doi: 10.1139/W08-099

Smith, C. A., O'maille, G., Want, E. J., Qin, C., Trauger, S. A., Brandon, T. R., et al. (2005). METLIN: a metabolite mass spectral database. Ther. Drug Monit. 27, 747-751. doi: 10.1097/01.ftd.0000179845.53213.39

Soares, S. C., Abreu, V. A., Ramos, R. T., Cerdeira, L., Silva, A., Baumbach, J., et al. (2012). PIPS: pathogenicity island prediction software. PLOS ONE 7:e30848. doi: 10.1371/journal.pone.0030848

Srinivasiah, S., Bhavsar, J., Thapar, K., Liles, M., Schoenfeld, T., and Wommack, K. E. (2008). Phages across the biosphere: contrasts of viruses in soil and aquatic environments. Res. Microbiol. 159, 349-357. doi: 10.1016/j.resmic.2008. 04.010

Sullivan, M. B., Krastins, B., Hughes, J. L., Kelly, L., Chase, M., Sarracino, D., et al. (2009). The genome and structural proteome of an ocean siphovirus: a new window into the cyanobacterial 'mobilome'. Environ. Microbiol. 11, 2935-2951. doi: 10.1111/j.1462-2920.2009.02081.x

Sundell, G. N., and Ivarsson, Y. (2014). Interaction analysis through proteomic phage display. Biomed. Res. Int. 2014:176172. doi: 10.1155/2014/176172

Suttle, C. A. (2007). Marine viruses-major players in the global ecosystem. Nat. Rev. Microbiol. 5, 801-812. doi: 10.1038/nrmicro1750

Tabb, D. L., McDonald, W. H., and Yates, J. R. III. (2002). DTASelect and Contrast: tools for assembling and comparing protein identifications from shotgun proteomics. J. Proteome Res. 1, 21-26. doi: 10.1021/pr0 $15504 \mathrm{q}$

Tamakoshi, M., Murakami, A., Sugisawa, M., Tsuneizumi, K., Takeda, S., Saheki, T., et al. (2011). Genomic and proteomic characterization of the large Myoviridae bacteriophage varphiTMA of the extreme thermophile Thermus thermophilus. Bacteriophage 1, 152-164. doi: 10.4161/bact.1.3.16712
Tamura, K., Stecher, G., Peterson, D., Filipski, A., and Kumar, S. (2013). MEGA6: Molecular Evolutionary Genetics Analysis version 6.0. Mol. Biol. Evol. 30, 2725-2729. doi: 10.1093/molbev/mst197

Tang, F., Barbacioru, C., Wang, Y., Nordman, E., Lee, C., Xu, N., et al. (2009). mRNA-Seq whole-transcriptome analysis of a single cell. Nat. Methods 6, 377-382. doi: 10.1038/nmeth.1315

Theodorescu, D., and Mischak, H. (2007). Mass spectrometry based proteomics in urine biomarker discovery. World J. Urol. 25, 435-443. doi: 10.1007/s00345-007-0206-3

Thurber, R. V., Haynes, M., Breitbart, M., Wegley, L., and Rohwer, F. (2009). Laboratory procedures to generate viral metagenomes. Nat. Protoc. 4, 470-483. doi: $10.1038 /$ nprot.2009.10

Uzoma, I., and Zhu, H. (2013). Interactome mapping: using protein microarray technology to reconstruct diverse protein networks. Genomics Proteomics Bioinformatics 11, 18-28. doi: 10.1016/j.gpb.2012.12.005

van Berkum, N. L., Lieberman-Aiden, E., Williams, L., Imakaev, M., Gnirke, A., Mirny, L. A., et al. (2010). Hi-C: a method to study the three-dimensional architecture of genomes. J. Vis. Exp. 39:e1869 doi: 10.3791/1869

Van den Bossche, A., Ceyssens, P.-J., De Smet, J., Hendrix, H., Bellon, H., Leimer, N., et al. (2014). Systematic identification of hypothetical bacteriophage proteins targeting key protein complexes of Pseudomonas aeruginosa. $J$. Proteome Res. 13, 4446-4456. doi: 10.1021/pr500796n

Vardi, A., Haramaty, L., Van Mooy, B. A., Fredricks, H. F., Kimmance, S. A., Larsen, A., et al. (2012). Host-virus dynamics and subcellular controls of cell fate in a natural coccolithophore population. Proc. Natl. Acad. Sci. U.S.A. 109, 19327-19332. doi: 10.1073/pnas.1208895109

Vardi, A., Van Mooy, B. A., Fredricks, H. F., Popendorf, K. J., Ossolinski, J. E., Haramaty, L., et al. (2009). Viral glycosphingolipids induce lytic infection and cell death in marine phytoplankton. Science 326, 861-865. doi: 10.1126/science.1177322

Vernikos, G. S., and Parkhill, J. (2006). Interpolated variable order motifs for identification of horizontally acquired DNA: revisiting the Salmonella pathogenicity islands. Bioinformatics 22, 2196-2203. doi: 10.1093/bioinformatics/btl369

Veses-Garcia, M., Liu, X., Rigden, D. J., Kenny, J. G., McCarthy, A. J., and Allison, H. E. (2015). Transcriptomic analysis of Shiga-toxigenic bacteriophage carriage reveals a profound regulatory effect on acid resistance in Escherichia coli. Appl. Environ. Microbiol. 81, 8118-8125. doi: 10.1128/AEM.02034-15

Villegas, A., She, Y. M., Kropinski, A. M., Lingohr, E. J., Mazzocco, A., Ojha, S., et al. (2009). The genome and proteome of a virulent Escherichia coli O157:H7 bacteriophage closely resembling Salmonella phage Felix O1. Virol. J. 6:41. doi: 10.1186/1743-422X-6-41

Vlahou, A., and Fountoulakis, M. (2005). Proteomic approaches in the search for disease biomarkers. J. Chromatogr. B. Analyt. Technol. Biomed. Life Sci. 814, 11-19. doi: 10.1016/j.jchromb.2004.10.024

Voorhies, A. A., Eisenlord, S. D., Marcus, D. N., Duhaime, M. B., Biddanda, B. A., Cavalcoli, J. D., et al. (2016). Ecological and genetic interactions between cyanobacteria and viruses in a low-oxygen mat community inferred through metagenomics and metatranscriptomics. Environ. Microbiol. 18, 358-371. doi: 10.1111/1462-2920.12756

Weinbauer, M. G., and Rassoulzadegan, F. (2004). Are viruses driving microbial diversification and diversity? Environ. Microbiol. 6, 1-11. doi: 10.1046/j.1462-2920.2003.00539.x

Weston, A. D., and Hood, L. (2004). Systems biology, proteomics, and the future of health care: toward predictive, preventative, and personalized medicine. J. Proteome Res. 3, 179-196. doi: 10.1021/pr0499693

Wiseman, J. M., Ifa, D. R., Zhu, Y., Kissinger, C. B., Manicke, N. E., Kissinger, P. T., et al. (2008). Desorption electrospray ionization mass spectrometry: imaging drugs and metabolites in tissues. Proc. Natl. Acad. Sci. U.S.A. 105, 18120-18125. doi: $10.1073 /$ pnas.0801066105

Wommack, K. E., and Colwell, R. R. (2000). Virioplankton: viruses in aquatic ecosystems. Microbiol. Mol. Biol. Rev. 64, 69-114. doi: 10.1128/MMBR.64.1.69-114.2000

Wood, D. E., and Salzberg, S. L. (2014). Kraken: ultrafast metagenomic sequence classification using exact alignments. Genome Biol. 15:R46. doi: 10.1186/gb-2014-15-3-r46

Yilmaz, S., Allgaier, M., and Hugenholtz, P. (2010). Multiple displacement amplification compromises quantitative analysis of 
metagenomes. Nat. Methods 7, 943-944. doi: 10.1038/nmeth12 $10-943$

Yuan, Y., and Gao, M. (2016). Proteomic analysis of a novel bacillus jumbo phage revealing glycoside hydrolase as structural component. Front. Microbiol. 7:745. doi: 10.3389/fmicb.2016.00745

Zhang, A., Sun, H., Yan, G., Wang, P., and Wang, X. (2016). Mass spectrometrybased metabolomics: applications to biomarker and metabolic pathway research. Biomed. Chromatogr. 30, 7-12. doi: 10.1002/bmc.3453

Zhao, X., Chen, C., Shen, W., Huang, G., Le, S., Lu, S., et al. (2016). Global transcriptomic analysis of interactions between Pseudomonas aeruginosa and Bacteriophage PaP3. Sci. Rep. 6:19237. doi: 10.1038/srep19237
Conflict of Interest Statement: The authors declare that the research was conducted in the absence of any commercial or financial relationships that could be construed as a potential conflict of interest.

Copyright $\odot 2017$ Parmar, Gaikwad, Dhakephalkar, Kothari and Singh. This is an open-access article distributed under the terms of the Creative Commons Attribution License (CC BY). The use, distribution or reproduction in other forums is permitted, provided the original author(s) or licensor are credited and that the original publication in this journal is cited, in accordance with accepted academic practice. No use, distribution or reproduction is permitted which does not comply with these terms. 